\title{
A SALINIDADE DAS ÁGUAS SUPERFICIAIS E SUBTERRÂNEAS NA BACIA DA GAMELEIRA, MUNICÍPIO DE AIUABA/CE
}

\section{SALINIZATION OF WATERS IN AIUABA, IN THE SEMIARID NORTHEAST OF BRAZIL}

\author{
Lucilene Pereira ${ }^{1}$, Maria Marlúcia Freitas Santiago ${ }^{1}$, \\ Horst Frischkorn ${ }^{2}$, José Carlos de Araújo ${ }^{2}$ e José Ossian Gadelha de Lima ${ }^{1}$
}

\begin{abstract}
Recebido em: 01/06/2006; aceito em: 10/10/2006
RESUMO As águas superficiais armazenadas em três açudes e as águas subterrâneas amostradas de três cacimbas, escavadas em aluvião, localizados em área com limitada ação antrópica na Bacia da Gameleira, no semi-árido do nordestino, foram estudadas através de medidas químicas e físico-químicas para identificar a origem dos sais dissolvidos nas águas e os processos de salinização. Os resultados mostram que os sais têm origem no processo de dissolução da interação água/rocha e nas precipitações atmosféricas; o efeito do processo de evaporação como agente de enriquecimento em sais é identificado nos dois tipos de armazenamentos, principalmente nas águas superficiais. As águas eram quimicamente adequadas ao consumo humano; porém, sofrem leve efeito da ação antrópica que se reflete na concentração de nitrato.
\end{abstract}

Palavras-Chave - Salinidade; aluvião; semi-árido; água subterrânea.

\begin{abstract}
Surface waters from three dams and groundwaters from three wells dug in alluvium, located in the Gameleira watershed in an area of restricted human action in the semi-arid Northeast of Brazil, were studied through chemical and physicochemical measurements for the identication of the origin of dissolved minerals and of the processes of salination. Results show that salts result from dissolution during water/rock interaction and from atmospheric precipitation. In both types of storage, evaporation is identified as an agent of salt enrichment, principally in surface waters. Waters sampled were chemically adequate for human consumption; however,anthropic action influences nitrate concentration.
\end{abstract}

Keywords - Salinity; alluvium; semi-arid; groundwater.

\section{INTRODUÇÃO}

A existência, no Semi-Árido do Nordeste brasileiro, de uma estação seca de cerca de seis meses, cria a necessidade de estocar água para suprimento no período de estiagem. Com esta finalidade, foi iniciado no final do século XIX, entre 1886 e 1889 , o primeiro programa de abastecimento durante o período de uma grande seca. Uma Comissão da Seca foi criada pelo Imperador D. Pedro II com a proposta de construção de açudes e reservatórios públicos; o primeiro açude a ser construído foi o Cedro, em Quixadá/CE, cuja construção foi iniciada em 1888 e concluída em 1906.

$\mathrm{Na}$ década de 1950, durante o governo de Juscelino Kubitschek, foram construídos grandes açudes no Ceará: Orós, Banabuiú, Araras e Pentecoste que, na estação seca, são utilizados para culturas de vazante, piscicultura e outras atividades econômicas realizadas em torno do açude (COGERH, 2000). Outro programa intensivo de abastecimento de água criado no Ceará foi o de perfuração de poços, iniciado na década de 1960, para atender a demanda nas áreas distantes dos açudes.

Embora açudes, cacimbas e poços passassem a contribuir significativamente para $o$ abastecimento hídrico da região, deparou-se com um novo problema: a qualidade das águas, que em muitos dos reservatórios não é adequada ao consumo humano. Nos açudes, elas ficam sujeitas à elevadas taxas de evaporação, tornando-se salinas, atingindo, em alguns casos, concentrações de sais tais que impedem o seu uso para consumo humano e na agricultura.

Trabalho realizado por Santiago (1984) em dois açudes do Ceará mostrou a contribuição dos processos de lixiviação de sais na bacia hidrográfica durante a chegada das primeiras chuvas, que aumenta a massa de sais, e da evaporação, que eleva a concentração destes no reservatório. Este trabalho mostrou também a necessidade de um gerenciamento adequado no período seco, para que a entrada de água no período de chuvas dilua os sais armazenados, deixando as águas em níveis de salinidade satisfatórios.

\footnotetext{
${ }^{1}$ Departamento de Física da UFC (lucilene@fisica.ufc.br) (marlucia@fisica.ufc.br)(ossian@uece.br)

${ }^{2}$ Departamento de Engenharia Hidráulica e Ambiental da UFC (cariri@ufc.br) (jcaraujo@ufc.br)
} 
Estudos sobre a qualidade das águas subterrâneas no Ceará (QUEIROZ et al. 1999; RIBEIRO et al., 2000; TEIXEIRA et al., 2001; MACHADO et al., 2002; SANTIAGO et al., 2003) mostram que nas áreas de cristalino, que representam $75 \%$ do Estado, as águas são, em geral, de elevada salinidade e de uso restrito. Trabalhos foram realizados também, para identificar a origem dos sais e os processos responsáveis pela elevação da concentração salina (FRISCHKORN; SANTIAGO, 2000; AGUIAR et al. 2000). Em algumas áreas, a predominância de águas cloretadas sódicas é causada, principalmente, pela dissolução dos evaporitos (SOUZA FILHO et al., 2004), identificada em várias áreas do Ceará.

A pesquisa aqui relatada foi desenvolvida na Bacia da Gameleira, município de Aiuaba/CE, numa área de proteção ambiental, onde a ação antrópica é pequena, com o objetivo de identificar, os processos naturais de salinização e a qualidade das águas nestas condições.

\section{ÁREA DE TRABALHO}

A área de trabalho localiza-se no sudoeste do Ceará, no município de Aiuaba, e compreende parte da Bacia Experimental da Gameleira (Figura 1), uma das sete bacias que integram o projeto IBESA (Implantação de Bacias Experimentais no Semi-Árido), que teve como objetivo principal a criação da Rede de Hidrologia do Semi-Árido (REHISA) no Nordeste brasileiro, para desenvolver pesquisas aplicando metodologias unificadas visando conhecimento científico e tecnológico. A bacia está inteiramente inserida na Estação Ecológica de Aiuaba, administrada pelo IBAMA; por esse motivo, não sofre grande interferência antrópica, apresentando elevado nível de conservação.

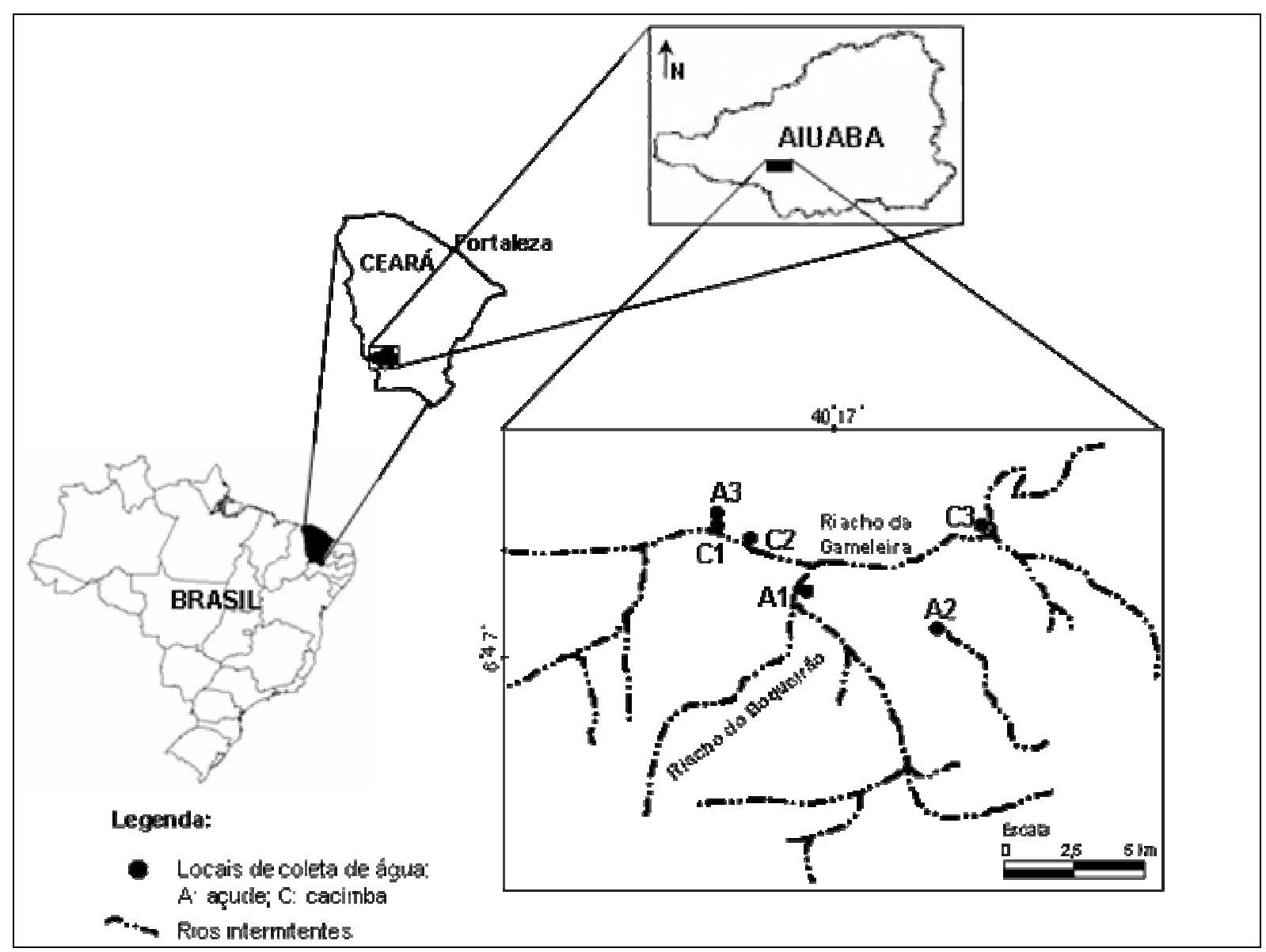

Figura 1- Localização da Bacia da Gameleira e dos pontos de amostragem. A: açude, C: cacimba Figure 1- Location of the Gameleira watershed with sampling points in the working area (rightangled insert); A:dam, B:dug well 
A temperatura média anual na região é de $26,0{ }^{\circ} \mathrm{C}$, com médias mensais variando de $24,5{ }^{\circ} \mathrm{C}$ em junho e julho a $27,8^{\circ} \mathrm{C}$ em novembro. $\mathrm{O}$ ar é seco, apresentando umidade relativa média anual de $61,6 \%$ com um mínimo no mês de setembro: 44,0\% (DNMET).

Os solos da bacia são do tipo Latossolo de textura argilosa e média, fase floresta/caatinga de relevo plano, associação de Bruno Não-Cálcico com textura argilosa, fase pedregosa de relevo suave e ondulado; associação de Planossolo Solódico com textura arenosa e média, fase pedregosa e rochosa de relevo suave ondulado com substrato gnaisse e granito e Solonetz Solodizado de textura arenosa e média de fase relevo plano (BRASIL, 1973).

Os principais cursos d'água que drenam a área são os riachos da Gameleira e do Boqueirão (Figura 1). $\mathrm{Na}$ área de estudo podem ser encontrados dois domínios hidrogeológicos: das rochas cristalinas, constituindo aqüíferos fissurais de baixa produção hídrica, e dos depósitos aluvionares, constituindo aqǘf́eros de sedimentos areno-argilosos recentes, de elevada produção hídrica em relação aos fissurais.

Reservas de água subterrânea estão presentes, principalmente, nos aluviões das calhas dos rios e riachos. De modo geral, estes depósitos representam uma boa alternativa como manancial, assumindo importância elevada sob o ponto de vista hidrogeológico diante da predominância de rochas cristalinas.

\section{Pontos de amostragem}

As amostras d'água foram coletadas em três açudes (A1, A2 e A3) e em três cacimbas (C1, C2 e C3). Por não existirem poços escavados ou piezômetros dentro das bacias hidrográficas dos açudes, foram coletadas amostras de cacimbas localizadas em áreas contíguas a estas. As características de cada ponto de amostragem são dadas na tabela 1.

Tabela 1- Características dos pontos amostrados. (A: açude, C: cacimba)

Table 1-Sampling point characteristics (A:dam, C:dug well)

\begin{tabular}{|c|c|c|c|c|c|c|c|}
\hline \multicolumn{2}{|l|}{ Manancial } & \multicolumn{2}{|c|}{$\begin{array}{l}\text { Localização } \\
\text { (UTM) }\end{array}$} & \multirow{3}{*}{$\begin{array}{c}\begin{array}{c}\text { Prof. } \\
(\mathrm{m})\end{array} \\
3\end{array}$} & \multirow{3}{*}{$\begin{array}{c}\text { Revestimento } \\
-\end{array}$} & \multirow{3}{*}{$\begin{array}{l}\text { Uso } \\
\text { ssedentação } \\
\text { le animais }\end{array}$} & \multirow{3}{*}{$\begin{array}{c}\text { Observações } \\
\begin{array}{c}\text { Regime } \\
\text { intermitente }\end{array}\end{array}$} \\
\hline & & \multirow{2}{*}{\begin{tabular}{|l}
$\mathrm{E}(\mathrm{m})$ \\
357323
\end{tabular}} & \multirow{2}{*}{\begin{tabular}{|l|}
$\mathrm{N}(\mathrm{m})$ \\
9259250
\end{tabular}} & & & & \\
\hline $\begin{array}{l}\text { Açude do } \\
\text { Boqueirão }\end{array}$ & A1 & & & & & & \\
\hline Açude do Caititu & A2 & 358911 & 9258749 & 6 & - & $\begin{array}{c}\text { Dessedentação } \\
\text { de animais }\end{array}$ & $\begin{array}{c}\text { Regime } \\
\text { intermitente }\end{array}$ \\
\hline $\begin{array}{l}\text { Açude da D. } \\
\text { Leontina }\end{array}$ & A3 & 356238 & 9260243 & 6 & - & Fins domésticos & Escavado à mão \\
\hline $\begin{array}{l}\text { Cacimba Casa } \\
\text { da Estação }\end{array}$ & $\mathrm{C} 1$ & 356254 & 9260099 & 14 & $\begin{array}{l}\text { Precário/ } \\
\text { rachaduras }\end{array}$ & Impróprio & $\begin{array}{l}\text { Presença de } \\
\text { animais }\end{array}$ \\
\hline $\begin{array}{l}\text { Cacimba } \\
\text { Antonio Fideles }\end{array}$ & $\mathrm{C} 2$ & 356644 & 9259904 & 14 & $\begin{array}{l}\text { Em boas } \\
\text { condições }\end{array}$ & Diversos fins & $\begin{array}{c}\text { Abastece } \\
\text { comunidades } \\
\text { vizinhas }\end{array}$ \\
\hline $\begin{array}{l}\text { Cacimba } \\
\text { Geraldo Nogueira }\end{array}$ & $\mathrm{C} 3$ & 359452 & 9260063 & 10 & $\begin{array}{c}\text { Sinais } \\
\text { de erosão }\end{array}$ & $\begin{array}{l}\text { Lavoura e fins } \\
\text { domésticos }\end{array}$ & Água salobra \\
\hline
\end{tabular}

\section{METODOLOGIA}

A amostragem para análise hidroquímica nos três açudes e nas três cacimbas, mostrados na figura 1, consistiu de seis campanhas no período de fevereiro a novembro de 2003. Em cada ponto de amostragem foi retirado o volume de $1,5 \mathrm{~L}$ armazenado em garrafas de $500 \mathrm{~mL}$. Todas as amostras foram conservadas por refrigeração em caixas de isopor com gelo, para que fossem mantidas as características físico-químicas.

Condutividade elétrica (CE) e $\mathrm{pH}$ foram determinados "in loco". As concentrações dos íns, $\mathrm{Ca}^{2+}, \mathrm{Mg}^{2+}, \mathrm{Na}^{+}, \mathrm{K}^{+}, \mathrm{Fe}^{2+}, \mathrm{Al}^{3+}, \mathrm{NH}_{4}^{+}, \mathrm{Cl}^{-}$, $\mathrm{SO}_{4}^{2-}, \mathrm{HCO}_{3}^{-}, \mathrm{CO}_{3}^{-}, \mathrm{OH}^{-}, \mathrm{NH}_{3}^{-}$e $\mathrm{NO}_{2}^{-}$foram determinadas no Laboratório de Hidroquímica do Departamento de Física da UFC. Os métodos utilizados na determinação destes íons obedecem ao Standard Methods [APHA, (1992)]. 


\section{RESULTADOS E DISCUSSÕES}

Os resultados das análises hidroquímicas das águas amostradas nos açudes e nas cacimbas estão apresentados na tabela 2.

As condutividades elétricas das amostras dos açudes são baixas, pois eles são pequenos reservatórios com renovação anual quase total de suas águas. No período de estiagem, chegam a diminuir de volume até atingir $\approx 5 \%$ de sua capacidade de armazenamento. O Açude da D. Leontina (A3), o menor deles, tem um volume aproximado de $576 \mathrm{~m}^{3}$.

A maioria das amostras dos açudes é do tipo bicarbonatada mista, como mostra o diagrama de Piper (Figura 2a), indicando a presença de águas novas provenientes de chuvas. Observa-se que no açude D. Leontina há predominância de bicarbonatadas cálcicas, o que pode ser atribuído ao maior tempo de contato com o solo argiloso local. Os açudes A1 e A2 apresentam forte variação sazonal da condutividade elétrica, o que não é observado no açude A3 (Figura 3a). Este último apresenta características de afloramento de água subterrânea.

A mudança de água bicarbonatada mista para bicarbonatada cálcica nos açudes é decorrente de processos de troca. Estudo dos solos na área feito por Mendonça et al. (2003) mostra, através da análise do complexo sortivo, que $\mathrm{Ca}^{2+} \approx \mathrm{Mg}^{2+}>$ $\mathrm{Na}^{+}$e que a condutividade elétrica é diretamente proporcional ao conteúdo de argila, do tipo caulinita, identificada pelos dados de Capacidade de Troca de Cátions e por análise de raios-X. A saturação de bases em 9 das 12 amostras analisadas é superior a 50\% indicando, também, alta saturação de cátions trocáveis.

As cacimbas foram escavadas nos aluviões dos riachos intermitentes, que só escoam nos períodos chuvosos e têm CE maiores do que as dos açudes. Nelas, as águas são bicarbonatadas mistas e cloretadas mistas, como mostra o diagrama de Piper (Figura 2b).

A cacimba de Antônio Fideles (C2) apresentou água do tipo cloretada mista em todo o período de estudo, certamente, explorando um aquífero de grande capacidade, já que o seu nível estático pouco variou durante o ano, mesmo com o seu uso contínuo para abastecimento de comunidades vizinhas, e a CE ficando constante durante todo o ano. A presença de água cloretada nas cacimbas indica águas quimicamente bem desenvolvidas. As variações sazonais da salinidade nas cacimbas são bem menores do que nos açudes (Figura 3b).

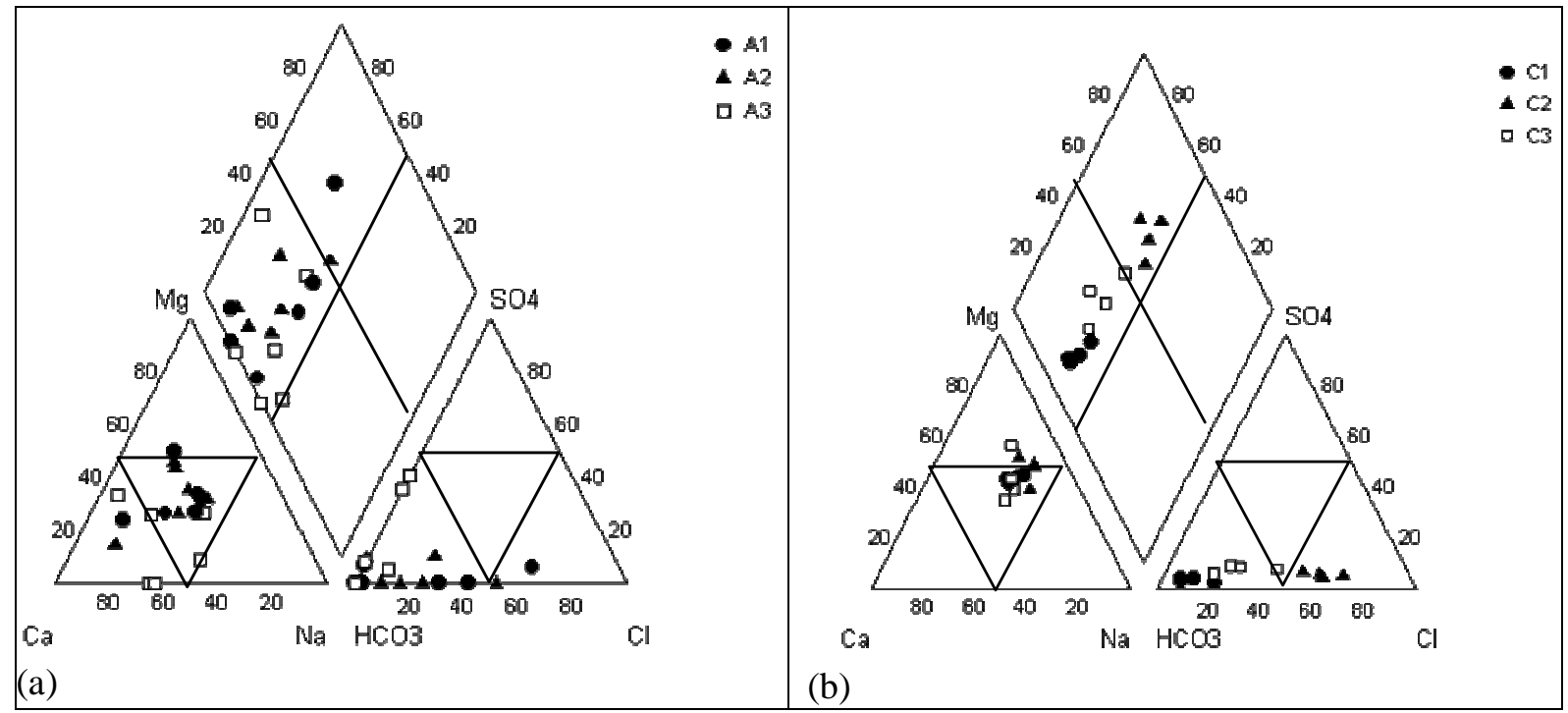

Figura 2- Diagramas de Piper para as águas superficiais e águas subterrâneas: (a) Açudes, (b) Cacimbas Figure 2- Piper plots for surface (a) and ground waters (b) 
Tabela 2- Análises físico-químicas e químicas de águas superficiais e de águas subterrâneas coletadas na Bacia da Gameleira- Aiuaba/CE (A: açude, C: cacimba)

Table 2- Results from physicochemical and chemical analyses of surface and ground waters sampled in the Gameleira watershed - Aiuaba / CE (A:dam, C:dug well)

\begin{tabular}{|c|c|c|c|c|c|c|c|c|c|c|c|c|c|}
\hline \multirow{2}{*}{$\begin{array}{c}\text { Data } \\
\text { Coleta }\end{array}$} & \multirow{2}{*}{ Amostra } & \multirow{2}{*}{$\begin{array}{c}\mathbf{C E} \\
(\mu \mathrm{S} / \mathbf{c m})\end{array}$} & \multirow{2}{*}{ pH } & \multirow{2}{*}{$\begin{array}{c}\text { STD } \\
(\mathrm{mg} / \mathrm{L})\end{array}$} & \multicolumn{9}{|c|}{ Concentração (mg/L) } \\
\hline & & & & & $\mathrm{Ca}^{2+}$ & $\mathbf{M g}^{2+}$ & $\mathrm{Na}^{+}$ & $\mathbf{K}^{+}$ & $\mathrm{Cl}^{-}$ & $\mathrm{SO}_{4}{ }^{2-}$ & $\mathrm{HCO}_{3}^{-}$ & $\mathrm{NO}_{3}^{-}$ & $\mathbf{N H}_{4}^{+}$ \\
\hline \multirow{6}{*}{ 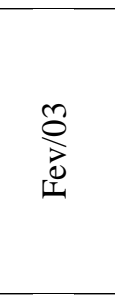 } & $2 \mathrm{~A} 1$ & 119 & 9,0 & 106 & 11,2 & 3,9 & 7,4 & 20,3 & 12,3 & 1,6 & 10,9 & 17,9 & 0,5 \\
\hline & $2 \mathrm{~A} 2$ & 117 & 7,2 & 156 & 6,4 & 5,3 & 4,6 & 13,0 & 12,8 & 7,2 & 59,1 & 38,1 & 2,1 \\
\hline & $2 \mathrm{~A} 3$ & 51 & 6,7 & 137 & 7,2 & 2,4 & 0,9 & 3,9 & 0,0 & 16,8 & 38,9 & 50,9 & 2,4 \\
\hline & $2 \mathrm{C} 1$ & 486 & 7,6 & 513 & 23,9 & 33,7 & 51,7 & 9,9 & 49,6 & 6,5 & 308,1 & 23,2 & 4,0 \\
\hline & $2 \mathrm{C} 2$ & 278 & 5,7 & 214 & 10,4 & 18,9 & 21,4 & 1,9 & 73,2 & 6,8 & 68,5 & 9,9 & 3,0 \\
\hline & $2 \mathrm{C} 3$ & 614 & 7,7 & 607 & 28,7 & 55,8 & 48,1 & 9,9 & 71,3 & 34,3 & 339,2 & 16,2 & 3,4 \\
\hline \multirow{3}{*}{ 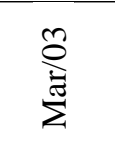 } & $3 \mathrm{~A} 1$ & 98 & 6,9 & 85 & 6,4 & 1,5 & 1,5 & 7,9 & 0,0 & 3,4 & 61,0 & 0,8 & 0,0 \\
\hline & $3 \mathrm{~A} 2$ & 81 & 6,7 & 70 & 4,0 & 0,5 & 1,0 & 3,9 & 0,0 & 3,9 & 50,0 & 4,9 & 1,0 \\
\hline & $3 \mathrm{~A} 3$ & 29 & 6,1 & 62 & 1,6 & 0,0 & 1,0 & 1,9 & 0,0 & 16,6 & 31,3 & 6,3 & 0,8 \\
\hline \multirow{3}{*}{ 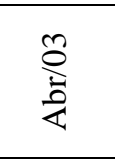 } & $4 \mathrm{~A} 1$ & 68 & 8,1 & 90 & 7,9 & 6,8 & 4,8 & 7,8 & 0,0 & 0,0 & 57,5 & 2,5 & 1,0 \\
\hline & $4 \mathrm{~A} 2$ & 64 & 7,4 & 81 & 6,4 & 4,8 & 4,8 & 6,5 & 2,9 & 0,0 & 47,5 & 2,5 & 1,7 \\
\hline & $4 \mathrm{~A} 3$ & 26 & 6,4 & 75 & 8,0 & 2,4 & 4,0 & 1,3 & 0,0 & 0,0 & 43,8 & 4,4 & 0,8 \\
\hline \multirow{6}{*}{ 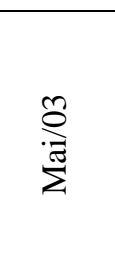 } & $5 \mathrm{~A} 1$ & 61 & 6,6 & 69 & 4,0 & 2,6 & 5,2 & 9,1 & 0,7 & 0,0 & 41,9 & 2,5 & 0,9 \\
\hline & $5 \mathrm{~A} 2$ & 73 & 7,1 & 77 & 6,4 & 2,4 & 5,7 & 7,8 & 4,9 & 0,0 & 41,9 & 2,9 & 0,9 \\
\hline & $5 \mathrm{~A} 3$ & 27 & 6,3 & 39 & 2,4 & 1,2 & 3,6 & 2,6 & 0,0 & 0,0 & 17,5 & 0,0 & 2,0 \\
\hline & $5 \mathrm{C} 1$ & 269 & 7,0 & 283 & 15,9 & 19,3 & 28,5 & 6,5 & 15,7 & 6,7 & 183,2 & 0,6 & 1,0 \\
\hline & $5 \mathrm{C} 2$ & 315 & 6,1 & 223 & 9,5 & 21,2 & 33,2 & 2,6 & 85,4 & 8,0 & 54,4 & 7,2 & 0,9 \\
\hline & $5 \mathrm{C} 3$ & 913 & 7,4 & 794 & 60,4 & 56,5 & 98,0 & 13,0 & 161,0 & 38,3 & 324,0 & 26,3 & 2,6 \\
\hline \multirow{6}{*}{ 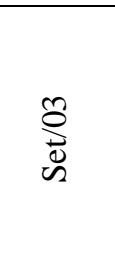 } & $6 \mathrm{~A} 1$ & 147 & 9,4 & 86 & 8,8 & 4,1 & 10,8 & 2,6 & 11,1 & 0,0 & 26,9 & 7,9 & 0,2 \\
\hline & $6 \mathrm{~A} 2$ & 110 & 8,4 & 107 & 7,2 & 4,6 & 7,8 & 10,4 & 10,1 & 0,0 & 52,5 & 9,7 & 0,0 \\
\hline & $6 \mathrm{~A} 3$ & 31 & 6,8 & 46 & 4,0 & 0,5 & 5,2 & 2,6 & 0,0 & 1,4 & 20,5 & 8,5 & 0,5 \\
\hline & $6 \mathrm{C} 1$ & 237 & 7,4 & 343 & 23,9 & 24,2 & 32,2 & 6,5 & 11,1 & 8,1 & 228,1 & 7,9 & 0,0 \\
\hline & $6 \mathrm{C} 2$ & 205 & 5,9 & 172 & 7,2 & \begin{tabular}{|l|}
16,5 \\
\end{tabular} & 24,5 & 2,6 & 52,5 & 6,7 & 51,2 & 10,9 & 0,0 \\
\hline & $6 \mathrm{C} 3$ & 750 & 7,4 & 722 & 63,9 & \begin{tabular}{|l|}
43,2 \\
\end{tabular} & 80,2 & 10,4 & 97,0 & 38,0 & 375,4 & 13,8 & 0,0 \\
\hline \multirow{6}{*}{$\frac{\hat{\sigma}}{a}$} & $7 \mathrm{~A} 1$ & 312 & 9,2 & 274 & 13,9 & 8,9 & 20,1 & 45,4 & 33,3 & 0,0 & 130,7 & 20,8 & 1,0 \\
\hline & $7 \mathrm{~A} 2$ & 192 & 6,9 & 141 & 8,3 & 5,5 & 13,5 & 18,1 & 32,3 & 0,0 & 51,2 & 6,3 & 1,3 \\
\hline & $7 \mathrm{~A} 3$ & 48 & 7,3 & 60 & 7,9 & 0,0 & 5,2 & 3,9 & 2,0 & 1,5 & 30,7 & 6,7 & 0,6 \\
\hline & $7 \mathrm{C} 1$ & 402 & 7,8 & 388 & 25,3 & 24,3 & 35,9 & 6,5 & 13,1 & 8,0 & 264,0 & 9,9 & 0,2 \\
\hline & $7 \mathrm{C} 2$ & 229 & 6,0 & 165 & 9,5 & 11,5 & 23,5 & 2,6 & 43,4 & 7,1 & 56,4 & 10,2 & 0,6 \\
\hline & $7 \mathrm{C} 3$ & 753 & 7,6 & 652 & 42,0 & 44,7 & 63,7 & 2,6 & 59,6 & 24,6 & 402,3 & 10,7 & 0,8 \\
\hline
\end{tabular}

A maioria das amostras das cacimbas e dos açudes localiza-se no lado esquerdo do losango dos diagramas de Piper (Figura 2), que indica águas do tipo bicarbonatada cálcica ou magnesiana, características de águas novas.

As variações das condutividades elétricas com o tempo para as águas dos açudes e das cacimbas, com a indicação do tipo químico, podem ser vistas nas figuras $3 b$ e $3 c$, respectivamente. $\mathrm{O}$ efeito dos períodos chuvoso e seco sobre a salinidade das águas pode ser observado comparando estas variações com as precipitações durante $o$ período de coletas, fevereiro a novembro de 2003. Os dados de chuva foram obtidos na estação pluviométrica instalada pela FUNCEME na Estação Ecológica de Aiuaba. As águas dos três açudes eram bicarbonatadas em todo o período, com exceção de duas amostras cloretadas mistas (2A1 e 7A2). Durante o período de observação, a condutividade elétrica aumentou 2,6 vezes no açude A1 e 1,6 vezes no açude A2 e permaneceu aproximadamente a mesma no açude A3. Este açude teve seu volume reduzido drasticamente até o mês de novembro. Essa diminuição foi causada pelo rebaixamento do nível freático no aqüífero ao qual este açude está ligado.

As águas nas cacimbas variaram de tipo químico durante o período, alternando entre águas cloretadas e bicarbonatadas mistas; todas elas apresentaram pequenas variações na condutividade elétrica, mas a cacimba $\mathrm{C} 3$ teve sempre valores bem mais elevados do que os de $\mathrm{C} 1$ e C2. Quanto aos cátions, as amostras 
são mistas em todo o período, com exceção de uma amostra magnesiana (2C3).

Apesar da baixa CE das águas da cacimba C1 ela não é utilizada pela comunidade devido ao seu péssimo estado de conservação e sanitário, e a presença de pequenos animais no interior dela. A cacimba C2 apresenta águas pouco mineralizadas e de boa qualidade; por isso, é utilizada para abastecimento.

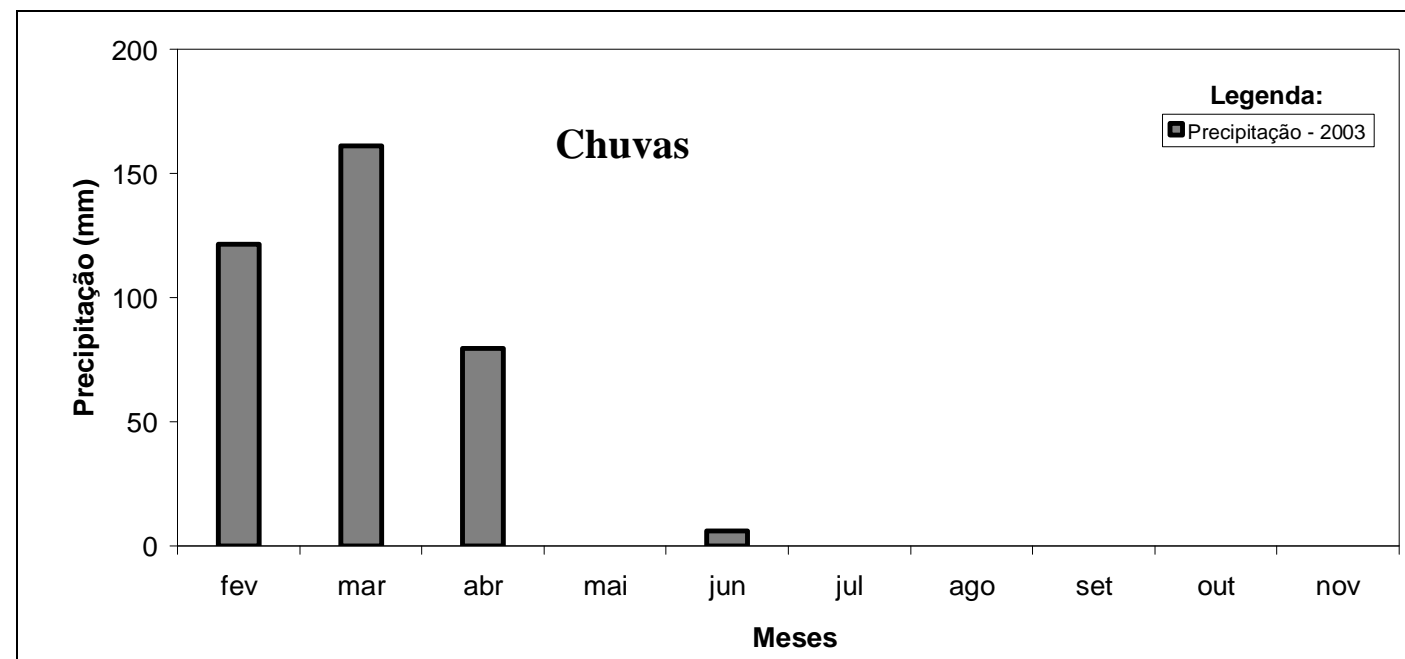

(a)

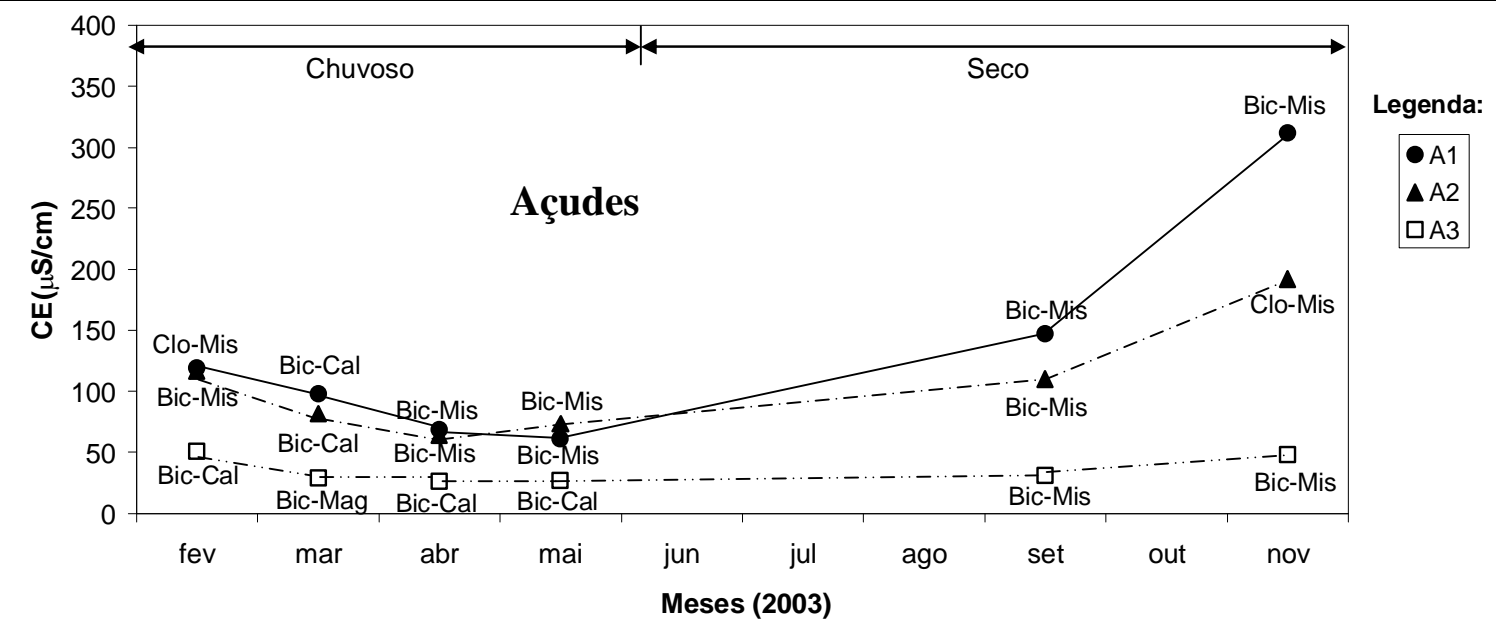

(b)

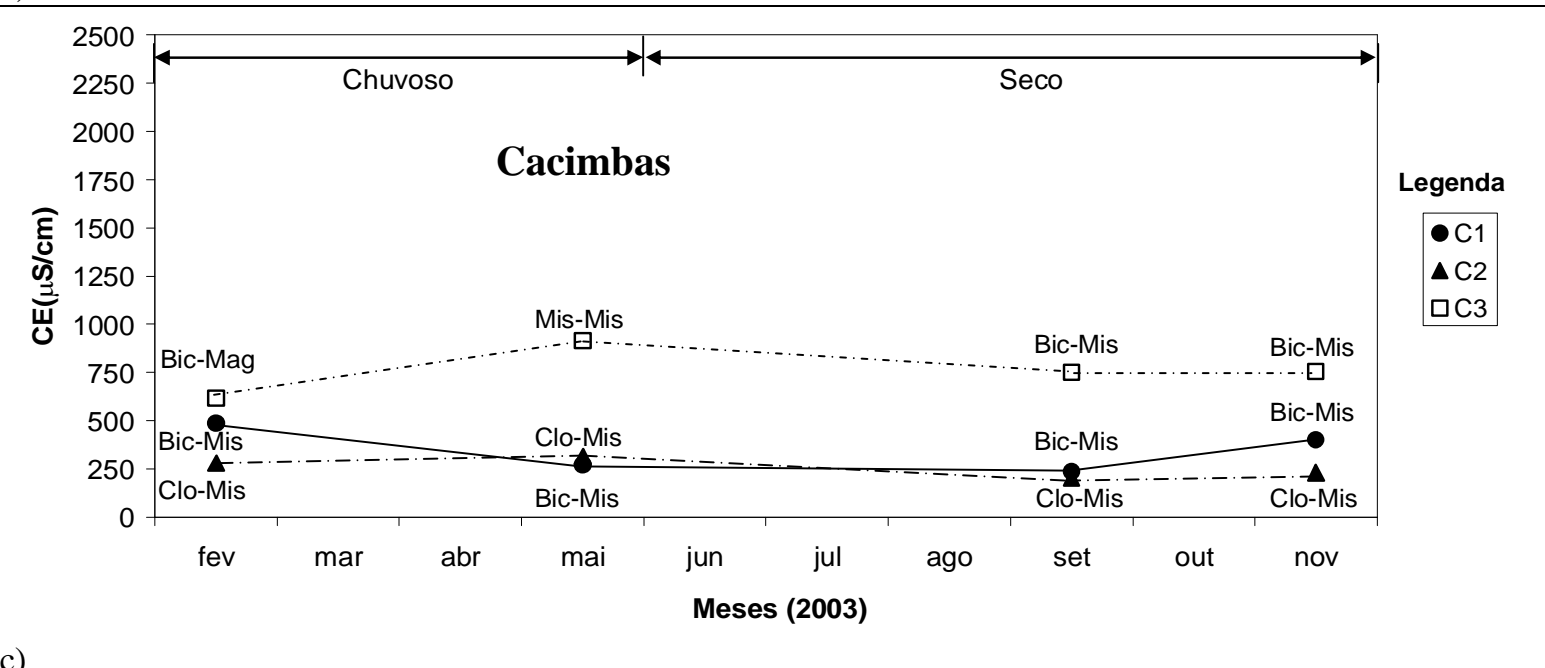

Figura 3- (a) Precipitação pluviométrica durante o período de coleta. Variação da condutividade elétrica e do tipo químico com o tempo (b) nos açudes e (c) nas cacimbas. Bic: bicarbonatada; Cal: cálcica; Clo: cloretada; Mag: magnesiana; Mis: mista.

Figure 3-Rainfall during the sampling period (a); electric conductivity variations in surface (b) and ground waters (c). Piper plot chemical types are indicated by: Bic-bicarbonate, Cal-calcium, Clo-chloride, Mag-magnesium, Mis-mixed 
$\mathrm{O}$ açude A1 apresentou, em quatro das seis coletas, $\mathrm{pH}$ acima de 8 com valor máximo de 9,4; valores abaixo de 7 foram encontrados durante período chuvoso. Este açude recebe a drenagem de toda a bacia trazendo argilas e outros minerais em suspensão que geram processos de troca com as águas do açude; há troca de cálcio e magnésio das águas com o sódio das argilas em suspensão, no período seco, tornando a água básica $(\mathrm{pH}$ em torno de 9).

Os açudes são utilizados diretamente por animais para sua dessedentação e também para consumo humano. A interferência desta ação sobre a qualidade das águas foi observada através da variação temporal dos íons nitrato $\left(\mathrm{NO}_{3}{ }^{-}\right)$e amônio $\left(\mathrm{NH}_{4}{ }^{+}\right)$(Figura 4). O nitrato representa o estágio final da oxidação do nitrogênio orgânico, orgânico que inicia com a ação das bactérias do grupo nitrossomonas oxidando o amônio para nitrito e depois para nitrato sob ação de bactérias autótrofas do grupo nitrobactérias.

$\mathrm{O}$ gráfico mostra que as concentrações de amônio são muito menores do que as de nitrato e que essas concentrações pouco variam, o que indica fonte contínua de amônio produzindo concentração média de $0,82 \pm 0,67(\mathrm{mg} / \mathrm{L})$. O açude D. Leontina (A3) apresentou uma amostra com concentração de nitrato de $50,9 \mathrm{mg} / \mathrm{L}$ no final do período seco; esse valor está acima do limite máximo permitido pelo CONAMA (1986), que é de $45 \mathrm{mg} / \mathrm{L}$. As concentrações elevadas dos íons nitrato $\left(\mathrm{NO}_{3}{ }^{-}\right)$e amônio $\left(\mathrm{NH}_{4}{ }^{+}\right)$são observadas no final da estação seca e no início das chuvas quando as margens do açude, muito visitadas pelos animais no período seco, são reinundadas.

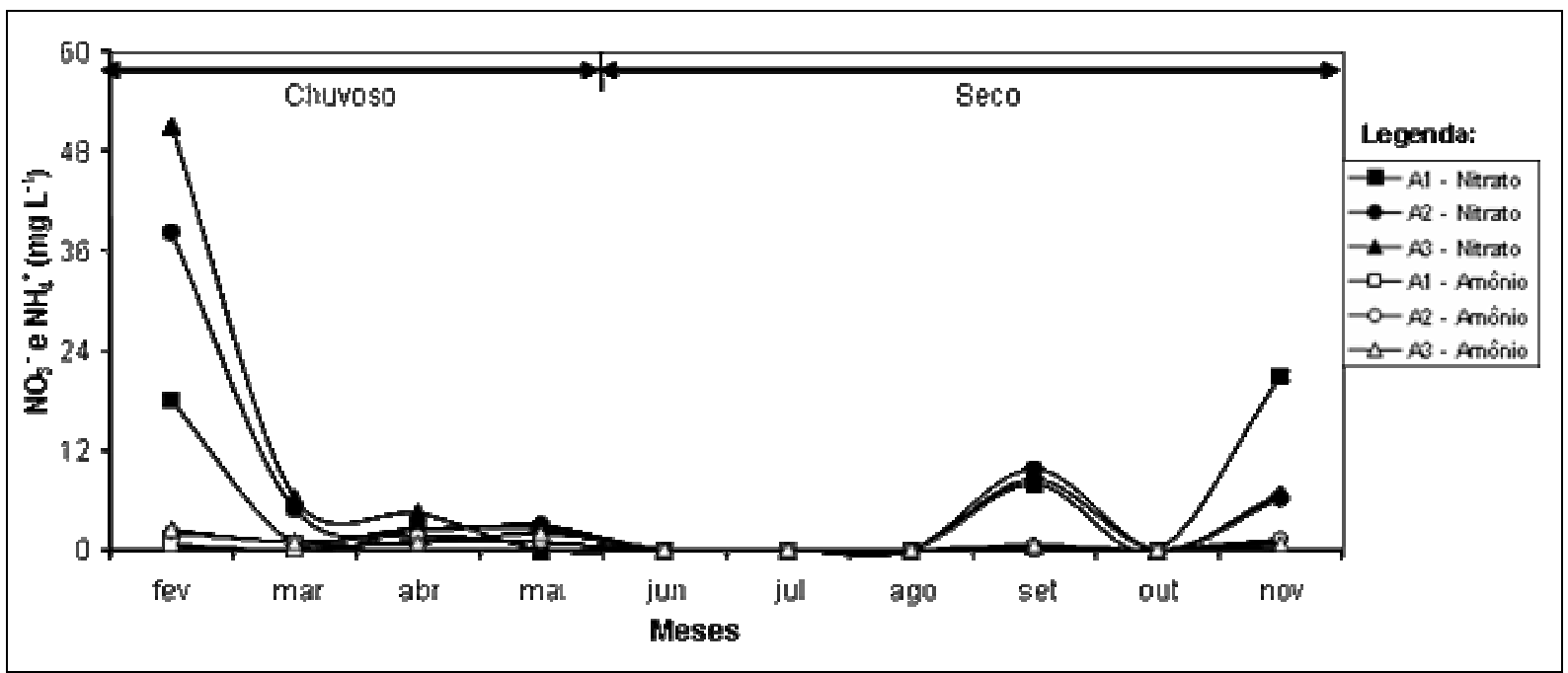

Figura 4- Variação temporal das concentrações dos íons amônio e nitrato nos açudes

Figure 4- Variation of ammonium and nitrate concentrations in dam waters

Os sais dissolvidos nas águas armazenadas nos açude e nas águas subterrâneas explotadas pelas cacimbas podem ter origens diferentes, como também, a salinidade destas águas pode ser decorrente de diferentes processos. O modelo de Gibbs (1970) foi proposto como ferramenta para estudar a química das águas superficiais que é controlada por três processos: intemperismo, precipitação atmosférica e evaporação/cristalização. A tabela 3 apresenta as características desses processos.

Tabela 3- Características dos processos no modelo de Gibbs. STD: Sólidos Totais Dissolvidos Table 3- Characteristics of Gibbs model processes (STD: Total Dissolved Solids)

\begin{tabular}{l|c|c|l}
\hline Processo & STD (mg/L) & $\begin{array}{c}\text { Localização } \\
\text { no bumerangue }\end{array}$ & Observações \\
\hline Precipitação atmosférica & Baixo & Parte inferior & Mistura com águas bicarbonatadas mistas \\
\hline Intemperismo & Médio & Parte central & Água recebe cálcio e bicarbonato \\
\hline Evaporação/Cristalização & Alto & Parte superior & Precipitação da calcita \\
\hline
\end{tabular}


Diagramas de Gibbs com amostras dos açudes são apresentados na figura 5; neles a maioria das amostras encontra-se na parte central do "bumerangue" indicando domínio de interação água/rocha. As amostras do açude A3 tendem para a parte inferior dos "bumerangues" catiônico e aniônico indicando forte influência de águas de chuva; os baixos valores da razão iônica decorrem do alto percentual de água de chuva no açude como foi constatado pela baixa CE.

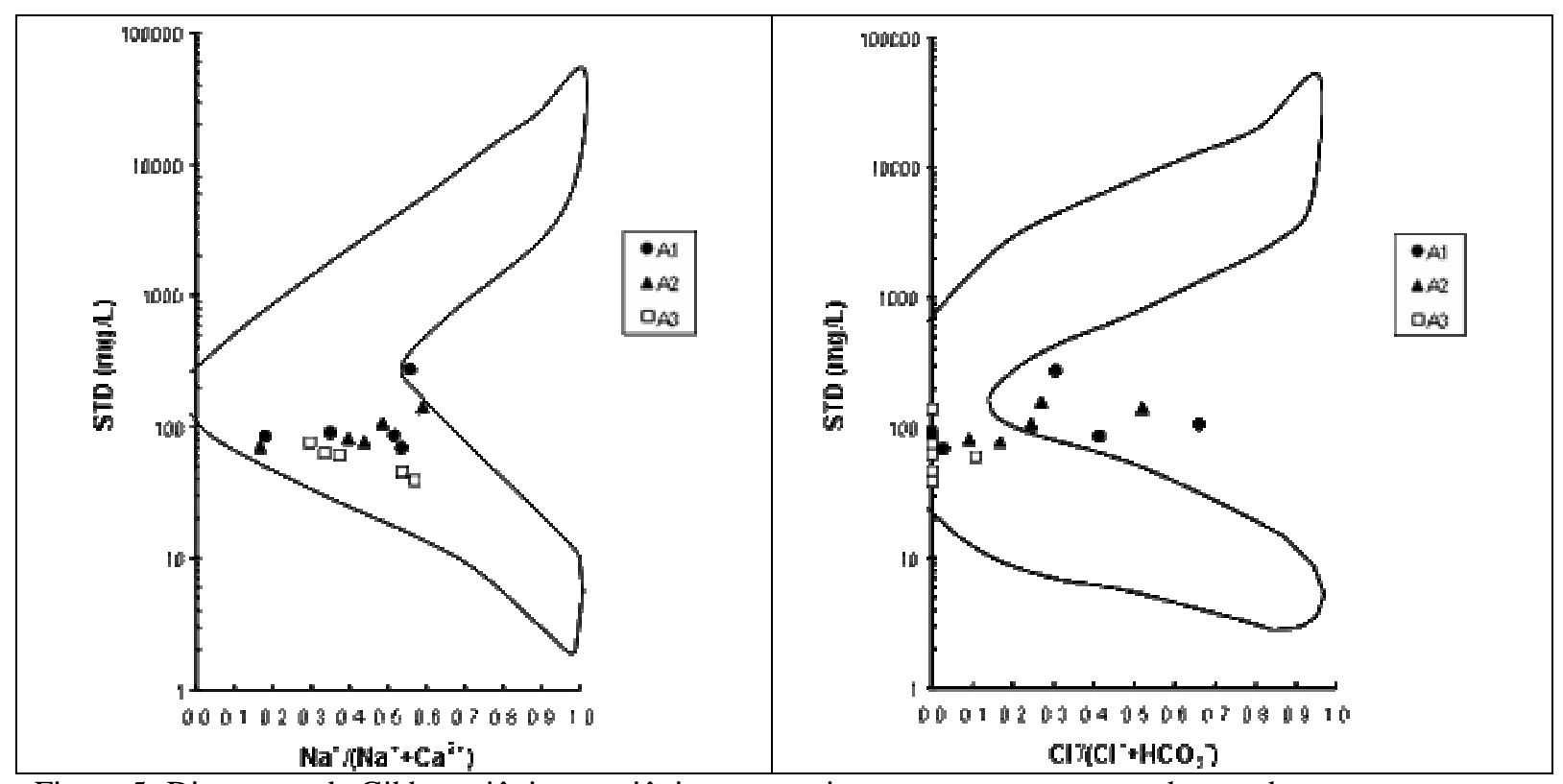

Figura 5- Diagramas de Gibbs catiônico e aniônico, respectivamente, com amostras dos açudes

Figure 5- Gibbs plots for cations and anions in dam waters

$\mathrm{Na}$ figura 6, com os dados das cacimbas, observa-se que as amostras de $\mathrm{C} 1$ estão na parte central dos bumerangues indicando processo de intemperismo. As amostras da cacimba C2 localizam-se fora dos bumerangues catiônico e aniônico; esse comportamento pode ser explicado pelo processo de precipitação atmosférica/ evaporação. São águas derivadas das chuvas, pouco mineralizadas que sofreram evaporação, deslocando-se verticalmente para a parte superior do bumerangue sem mudar de composição química. As amostras da cacimba C3 concentramse na parte superior do bumerangue, indicando que o processo de intemperismo é importante.

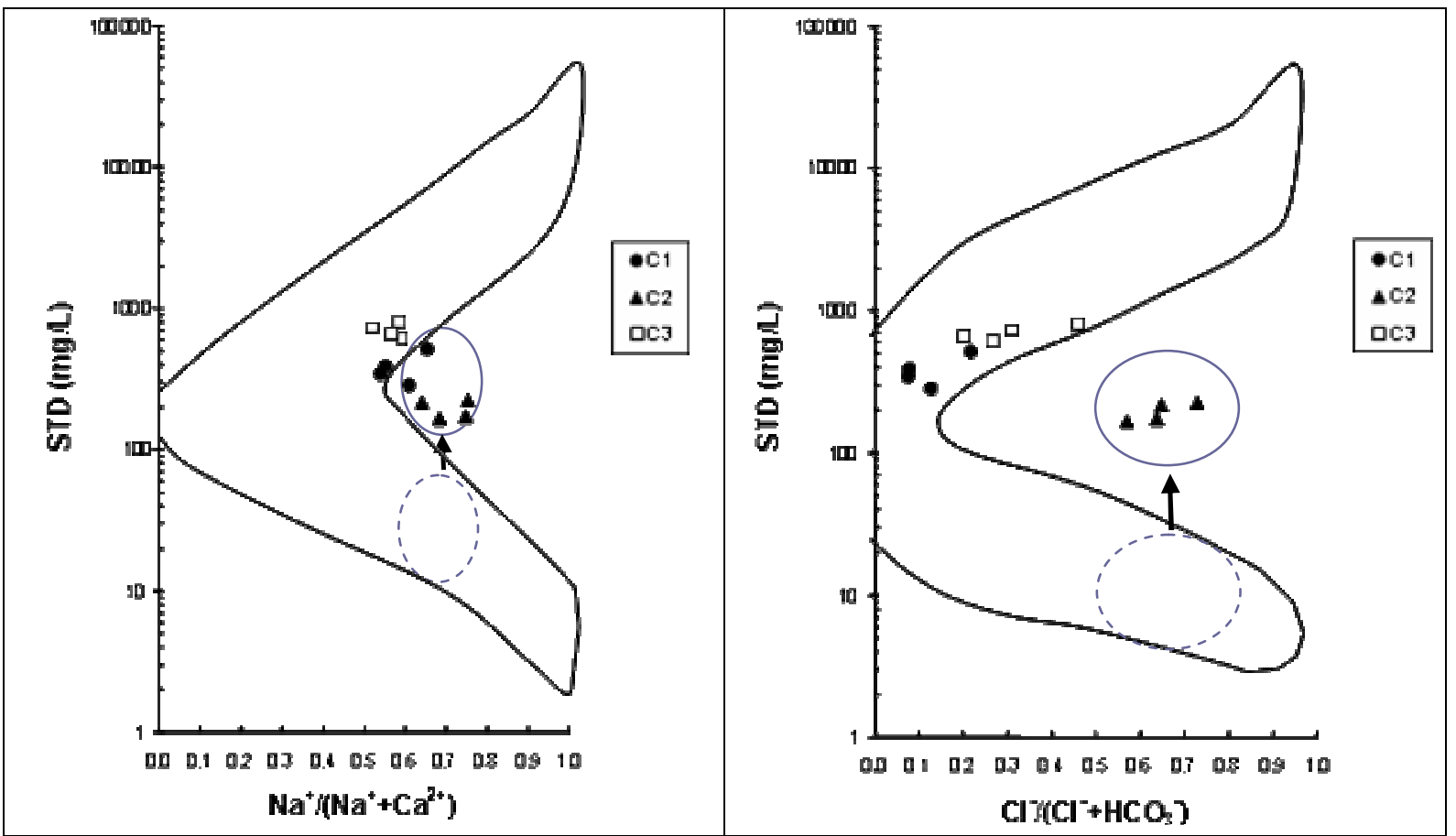

Figura 6- Diagramas de Gibbs catiônico e aniônico, respectivamente, com amostras das cacimbas Figure 6- Gibbs plots for cations and anions in ground waters 


\section{CONCLUSÕES}

As baixas concentrações de sais nas águas armazenadas nos açudes refletem a quase total renovação anual no período chuvoso, o que produz água de boa qualidade para o consumo humano.

Embora apresentando elevação da concentração de sais no período sem chuvas por efeito da evaporação, as águas dos açudes mostraram-se sempre águas doces $(\mathrm{CE}<500 \mu \mathrm{S} / \mathrm{cm})$.

No Açude do Boqueirão (A1), que recebe água da maior bacia hidrográfica, o processo de troca de cátions ocorrido nas argilas é o principal responsável pelos sais nas águas.

A salinidade mais elevada das águas subterrâneas amostradas nas cacimbas, escavadas no aluvião, é reflexo da menor renovação das águas do aqüífero do que nos açudes. $\mathrm{O}$ processo de evaporação contribui menos para a salinidade destas águas, por isso, a variação sazonal da concentração de sais é menor do que nos açudes.

Embora expostas às mesmas condições climáticas, as águas armazenadas superficialmente e as subterrâneas mostraram diferentes origens dos sais nelas contidos. No aluvião, predominam sais provenientes da interação água/rocha, ou seja, do processo de intemperismo. No açude com menores valores de condutividade elétrica (A3), os sais têm origem atmosférica, ou seja, das chuvas e de lixiviação dos solos.

Portanto, a química das águas nos açudes é controlada principalmente pela interação água/rocha. Nas três cacimbas, no aluvião, os processos dominantes são em duas o intemperismo, mais intenso numa delas do que na outra, e na terceira, domina a evaporação de águas de chuva.

O uso direto das águas dos açudes para dessedentação de animais é a origem dos elementos nitrogenados carreados através da lavagem do solo durante o período chuvoso e concentrado por evaporação no período seco.

\section{AGRADECIMENTOS}

Agradecemos ao IBAMA, à equipe técnica do projeto IBESA pelo apoio logístico durante as viagens de campo, à FUNCAP e à CAPES pelo apoio financeiro. 


\section{REFERÊNCIAS}

AGUIAR, R.B.; SANTIAGO, M.M.F.; J MENDES FILHO; J. e FRISCHKORN, H. A origem dos sais nas águas subterrâneas dos aqüíferos costeiros no município de Caucaia - Ceará. In: $1^{\circ}$ CONGRESSO MUNDIAL INTEGRADO DE ÁGUAS SUBTERRÂNEAS. Anais... Fortaleza: 2000.

APHA (American Public Health Association) Standard Methods for the examination of water and wastewater 18 ed., 1992.

BRASIL. Levantamento exploratório Reconhecimento dos solos do Estado do Ceará (Boletim Técnico, 28 - Série Pedologia, 16). Recife: Departamento Nacional de Pesquisa Agropecuária Divisão de Pesquisa Pedológica,1973.

COGERH. Companhia de Gerenciamento de Recursos Hídricos. Histórico Político das Águas Disponível em: <http: //www.cogerh.com.br/versao3/publicgestao.asp?page=gestao2>. Acesso em: 02/05/2006.

CONAMA- Conselho Nacional do Meio Ambiente. RESOLUÇÃO no 20 de 18 de junho de 1986. Diário Oficial da União da República Federativa do Brasil, Brasília, DF, 30 de julho de 1986. Disponível em:<http://www.mma.gov.br/pot/conama/res/res86/res 0186.html>. Acesso: 25/05/2006.

DNMET. Departamento Nacional de Meteorologia do Ministério da Agricultura e Reforma Agrária. Normas climatológicas, Brasília - DF, (1961 - 1990).

FRISCHKORN, H.; SANTIAGO, M.F. Mechanisms of salinization in the Northeast of Brazil. In: GERMAN-BRAZILIAN WORKSHOP ON NEOTROPICAL ECOSYSTEMS. Anais... Hamburg: 2000.

GIBBS, R. Mechanisms controlling world water chemistry. Science v.170, p.1088-1090, 1970.

MACHADO, C.J.F.; SANTIAGO, M.M.F.; MENDONÇA, L.A.R.; FRISCHKORN, H.; MENDES FILHO, J. Evolução da salinidade das águas subterrâneas no aqüífero Mauriti - Bacia Sedimentar - do Araripe. XII CONGRESSO BRASILEIRO DE ÁGUAS SUBTERRÂNEAS. Anais... Florianópolis: 2002.
MENDONÇA, L.A.R.; PEREIRA, L.; SANTIAGO, M.F.; FRISCHKORN, H. de ARAÚJO, J.C., MENDES FILHO, J. e LIMA, J.O.G de, (2003). Qualidade das águas superficiais e subterrâneas da Bacia da Gameleira - Aiuaba no cristalino cearense. XII CONGRESSO BRASILEIRO DE ÁGUAS SUBTERRÂANAS. Anais... Florianópolis: 2002.

PEREIRA, L. Estudo isotópico e hidroquímico das águas superficiais e subterrâneas no semi-árido cearense em área de preservação ecológica no município de Aiuaba. Tese de Doutorado, Departamento de Física, UFC, 123p. 2006

QUEIROZ, G.H. de; FRISCHKORN, H. SANTIAGO, M. M. F. Variação da qualidade da água de açudes e poços no município de Tauá-CE no período de junho de 1999 a junho de 2000. In: XIV SIMPÓSIO BRASILEIRO DE RECURSOS HÍDRICOS. Anais... Aracaju: 2001.

RIBEIRO, J.A.; MELO, F.; FEITOSA, F.A.C.; SILVA, M.S.V.; SANTIAGO, M.M.F. Contribuição hidroquímica para o conhecimento das bacias do Iguatu - CE. In: $1^{\underline{O}}$ CONGRESSO MUNDIAL INTEGRADO DE ÁGUAS SUBTERRÂNEAS. Anais...Fortaleza: 2000.

SANTIAGO, M.M.F. Mecanismos de salinização em regiões semi-áridas. Estudo dos açudes Pereira de Miranda e Caxitoré no Ceará. 1984. Tese (Doutorado) USP, São Paulo, 1984

SANTIAGO M.F.S.; FRISCHKORN, H.; MENDONÇA, L.A.R.; CORDEIRO, V.F.; BRITO, F.A. de., Monitoramento de um poço no cristalino em Caucaia/Ceará pela condutividade elétrica. XV SIMPÓSIO BRASILEIRO DE RECURSOS HÍDRICOS. Anais.... Curitiba: 2003.

SOUZA FILHO, O.A; VERÍSSIMO, L.S.; SILVA, C.M.S.V.; SANTIAGO, M.M.F. Medidas hidroquímicas nas águas subterrâneas da região de Irauçuba, Norte do Ceará. In: XIII CONGRESSO BRASILEIRO DE ÁGUAS SUBTERRÂNEAS. Anais... 2004.

TEIXEIRA, Z.A; SANTIAGO, M.M.F.; MENDES FILHO, J; FRISCHKORN, H. Estudo de águas subterrâneas representativas do município de Tauá. In: XIV SIMPÓSIO BRASILEIRO DE RECURSOS HÍDRICOS. Anais... Aracaju: 2001. 